\title{
Çocukluk çağı ayak osteokondrozları
}

\author{
Juvenile osteochondroses in foot
}

\author{
Kaya Hüsnü Akan
}

Bahçeşehir Üniversitesi Tıp Fakültesi, Ortopedi ve Travmatoloji Anabilim Dalı, İstanbul

Osteokondroz, büyümekte olan iskelet sistemini etkileyen bir grup bozukluk için kullanılan bir terimdir. Bu bozukluklar, anormal büyüme, yaralanma veya gelişmekte olan büyüme plağı ile onu çevreleyen ossifikasyon merkezlerinin aşırı kullanımı sonucu oluşur. Bu bozuklukların esas kaynağı bilinmemesine karşın, etiyolojisinde genetik bozukluklar, travmanın tekrarlaması, vasküler anomaliler, mekanik faktörler ve hormonal dengesizlikler sayılabilir. Bu hastalık grubunda, en sık rastlanılanları olan ayak naviküler osteonekrozu (Kohler hastalığı), kalkaneal (Sever) apofizit, 5. metatars bazis apofiziti (Iselin hastalığı) ve metatars başı infraksiyonu (Freiberg hastalığı) yer alır. Çocukluk çağı osteokondrozlar ve apofizitlerinin iyi bilinmesi, özellikle spor yapan pediatrik grubun artması ile, klinik uygulamalarda erken tanı ve tedavi sağlayarak erken spora dönüş ve hasta memnuniyeti sağlayacaktır.

Anahtar sözcükler: juvenil osteokondroz; apofiziti; Kohler; Sever; Iselin; Freiberg
The term osteochondrosis is used to define a couple of disorders that affect the growing skeleton. These disorders result from abnormal growth, injury, or overuse of the developing growth plate and surrounding ossification centers. Although the exact etiology of these disorders is unknown, genetic causes, repetitive trauma, vascular abnormalities, mechanical factors, and hormonal imbalances may all contribute as a factor. The most common disorders in this group are osteochodrosis of the tarsal naviculae (Kohler disease), calcaneal apophysitis (Sever disease), apophysitis of the 5th metatarsal (Iselin disease), and infraction of the metatarsal head (Freiberg disease). A thorough understanding of the juvenile osteochondroses and apophysitis will help early diagnosis and better treatment in the growing juvenile sports population which in turn will provide early return to sports and patient satisfaction.

Key words: juvenile osteochondrosis; apophysitis; Kohler; Sever; Iselin; Freiberg

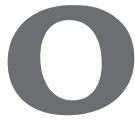
steokondroz, büyümekte olan iskelet sistemini etkileyen bir grup bozukluk için kullanılan bir terimdir. Bu hastalarda eklem ağrısının etiyolojisi genellikle osteokondrozise bağlı olsa da, travmatik, inflamatuvar veya enfeksiyöz olabilir. Osteokondrozlar, anormal büyüme, yaralanma veya gelişmekte olan büyüme plağı ile onu çevreleyen ossifikasyon merkezlerinin aşırı kullanımı sonucu oluşur. Genelde erkekler daha fazla etkilenir ve semptomlar 10-14 yaşlarında ortaya çıkar. Erkeklerin daha fazla etkilenmesinin nedeninin, çocukluk travmalarına ve aşırı kullanma yaralanmalarına daha çok maruz kalmaları olduğu düşünülmektedir. ${ }^{[1]}$ Patofizyolojisi kemik ve kıkırdak nekrozu ile başlar. Bu süreci, revaskülarizasyon ile granülasyon dokusu oluşumunun ve invazyonunun yeniden organizasyonu, nekrotik segmentlerin osteoklastik rezorpsiyonu takip eder ve son olarak da osteoid replasmanı ile, olgun lamellar kemik oluşumu ile biter. ${ }^{[2]}$

Apofizitler, kas tendon ünitelerinin kemiğe yapışma yerlerinde oluşan bir alt grubudur. Apofiz, direkt grafilerde de görülen aksesuvar bir kemikleşme merkezi olarak çıkar. Bu yapışma bölgesinde irritasyon sonucu oluşan çıkıntıya apofızit adı verilir. ${ }^{[3]}$

Bu bölümde, ayakta en sık görülen osteokondrozlar ve apofizitlerden, Kohler veya naviküler osteonekrozu, kalkaneus (Sever) apofiziti, 5. metatars bazis apofiziti (Iselin) hastalığı ve metatars başı infraksiyonu (Freiberg hastalığı) anlatılacaktır (Şekil 1).

- Illetişim adresi: Doç. Dr. Kaya Hüsnü Akan, Güzeller Mh., Kavak Cd No:5, 952/4., 41400 Gebze, Kocaeli Tel: 0262 - 6757575 e-posta: akan44@gmail.com

- Geliștarihi: 17 Kasım 2017 Kabul tarihi: 17 Kasım 2017 


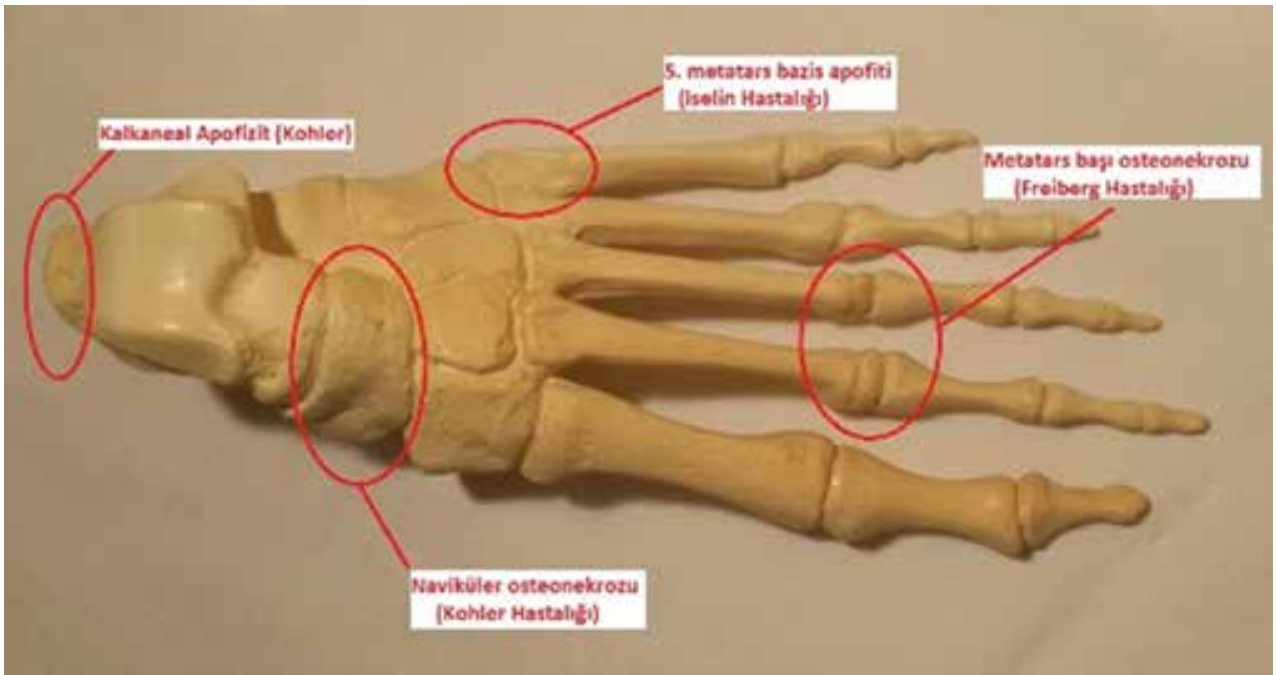

Şekil 1. Ayakta sık rastlanan osteokondrozlar ve apofizitler.
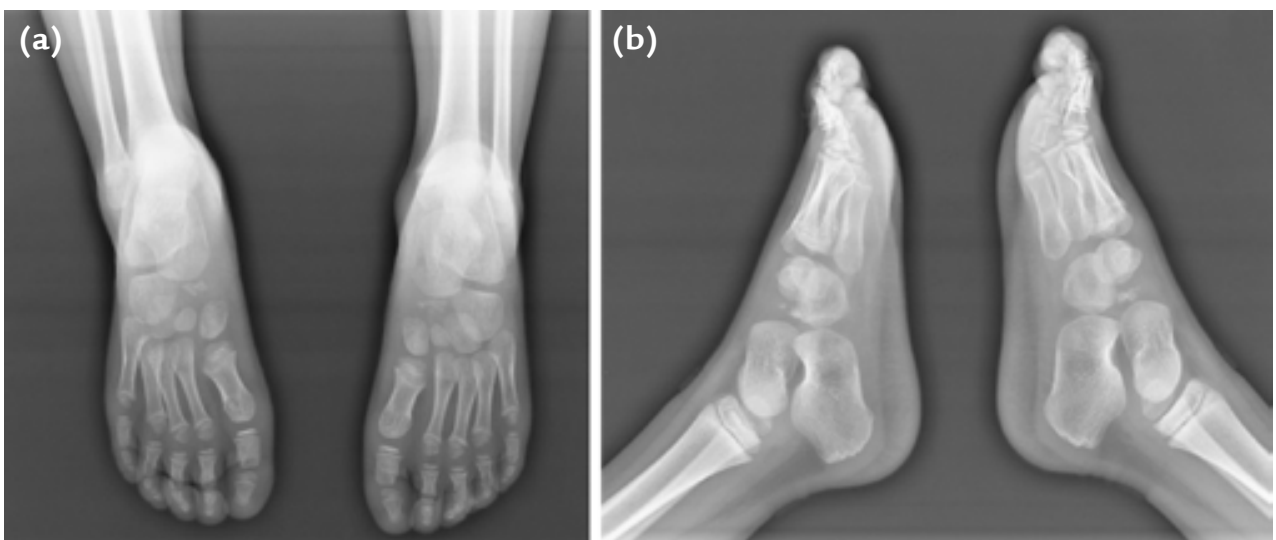

Şekil 2. Bilateral naviküler osteonekrozu (altı yaş, erkek çocuk): AP grafi (a); lateral grafi (b).

\section{KÖHLER HASTALIĞı}

\section{(TARSAL NAVIKÜLER OSTEOKONDROSIS)}

İlk olarak 1908'de Köhler tarafından tanımlanmış olan, 3-10 yaş grubunda daha çok erkek çocuklarda görülen, naviküler kemiğin avasküler nekrozudur. ${ }^{[4]}$ Ender olarak 2-4 yaşlarındaki kız çocuklarda da görülebilir. Olguların yaklaşık \%25’i bilateraldir. Hastalığın etiyopatogenezinin bilinmemesine karşın, erken ossifikasyon döneminde mekanik strese bağlı olarak hem osteogenez hem de kondrogenez ile birlikte enkondral ossifikasyonun bozulmasına bağlı olduğu düşünülmektedir. 1937'de Karp, naviküler kemiğin ossifikasyonunun kız çocuklarında erkek çocuklara göre daha erken gerçekleştiğini bulmuş, bunun da erkeklerde erken mekanik stres nedeniyle avasküler nekroza yol açtığını öne sürmüştür. ${ }^{[5]}$ Bunun yanı sıra, naviküler kemik erken ossifikasyon döneminde yalnızca besleyici arter yoluyla kanlanmasının daha sonra gelişen perikondrial damarlanmadan daha zayıf olmasının, vasküler yaralanmaları kolaylaştırdığı öne sürülmüştür. ${ }^{[6]}$ Histolojik olarak etkilenen kemiklerde vasküler yaralanma ile uyumlu olarak, nekroz, ölü kemik rezorpsiyonu, remodeling ile birlikte yeni kemik oluşumu görülmektedir.

\section{Klinik Bulgular - Radyoloji}

Köhler hastalığında erkek çocuk, topallama ve ayağının iç kısmını kollama yakınmasıyla başvurur. Hareket açıklıkları genellikle doğal olup mediyalde naviküler kemik üzerinde bazen enfeksiyon ve artrit ile karıştırılabilecek hafif kızarıklık ve ısı artışı ve mediyal ayak hassasiyeti görülür. Her iki ayağa çektirilen grafilerde, naviküler kemikte karakteristik bulgular olan skleroz, fragmantasyon ve yassılaşma görülür (Şekil 2). ${ }^{[7]}$ Naviküler kemik ossifikasyon merkezinde düzensizlikler görülebilir, ancak Köhler hastalığı radyolojik olmaktan çok bir klinik tanıdır; bu nedenle semptomu 


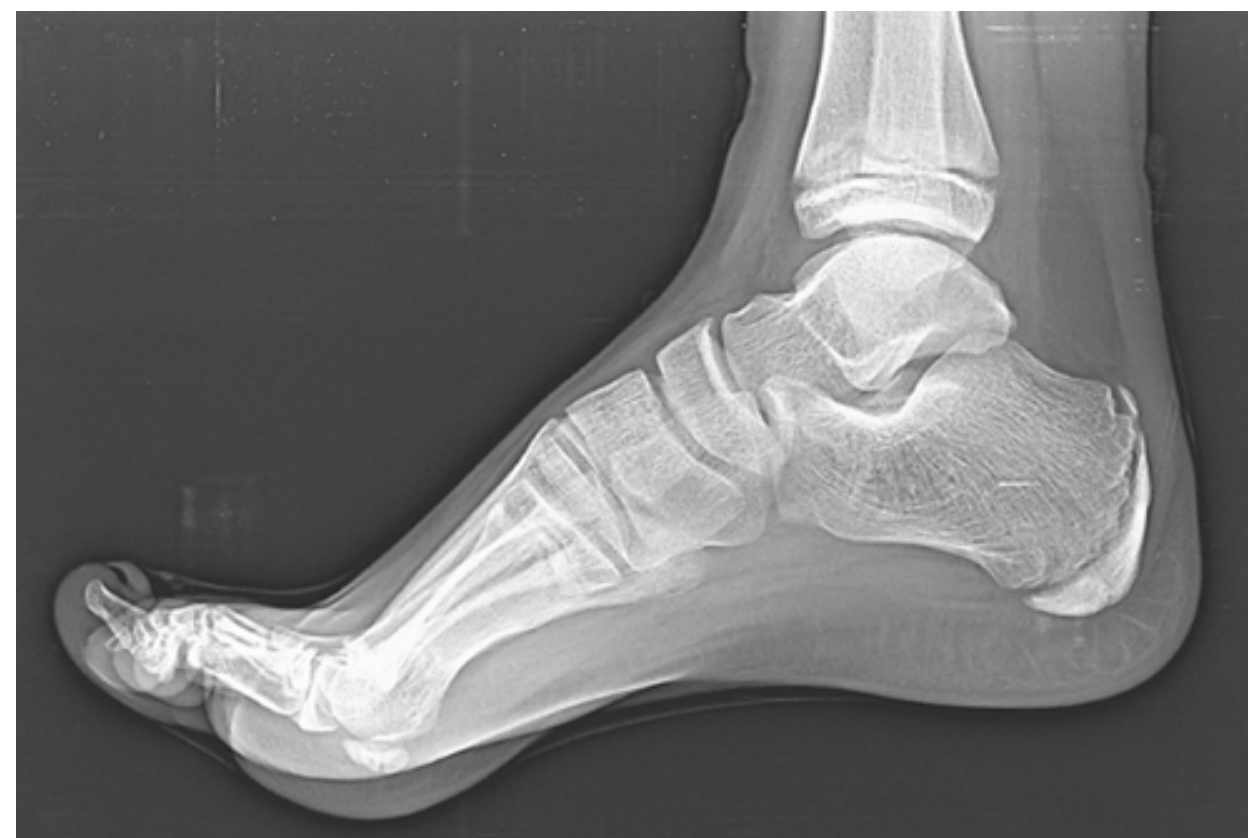

Şekil 3. Sever hastalığı (10 yaş, erkek çocuk); lateral grafi.

olmayan hastalara bu tanı konmaz. Ayırıcı tanı için manyetik rezonans (MR) görüntülemesi, enfeksiyon için hemogram, sedimentasyon ve CRP (C-reaktif protein) değerleri ile birlikte anlamlıdır. Ayırıcı tanıda yer alan stres kırıkları, diyabet avasküler nekrozu erişkinlerde görülür.

\section{Hastalık Seyri - Tedavi}

İyileşme spontan oluştuğu için semptomatik tedavi yeterlidir. Eğer ağrı çoksa 6-8 hafta kısa bacak yürüme alçısı önerilebilir. Uzun süreli takiplerde hastalığın sekel bırakmadan tamamen iyileştiği gösterilmiştir. ${ }^{[4,8]}$ Ağrısı devam eden hastalarda tarsal koalisyon gibi diğer tanılar aranmalıdır.

\section{KALKANEAL APOFIZIT (SEVER HASTALIĞI)}

Sever tarafından büyüyen çocuklarda kalkaneusun inflamatuvar bir bozukluğu olarak tanımlanan hastalık, görüntüleme yöntemlerinin gelişmesiyle birlikte, bir osteokondroz olarak belirlenmiştir. Hastalık, immatür sporcularda yaygın olarak görülen bir durumdur. Rastlanma yaşı ortalama 11,5 olup erkeklerde iki kat daha fazla görülmesine karşın, son yıllarda kızlarda spor aktivitelerinin artması nedeniyle bu fark azalmıştır. Genellikle bilateraldir ve en çok futbol oynayanlarda görülür. ${ }^{[9]}$
Eklem dışı bir osteokondroz olarak tanımlanan bu hastalıkta, Aşil tendonu ve plantar fasya fiziksel aktivite ile kalkaneal apofize tensil kuvvetler uygulamaktadır. Aynı zamanda özellikle yürümenin topuk vurma fazında direkt yük de almaktadır. Hem plantar fasyanın gerilmesi hem de gastroksoleus kompleksinin çekmesi sonucunda tekrarlayan travma ile mikro-kırıklar oluşmakta, bu nedenle stres kırı̆ı meydana gelmektedir. ${ }^{[10]}$

\section{Klinik Bulgular - Radyoloji}

Sever apofizitinde tipik hasta 10-12 yaşlarındaki spora yatkın çocuktur. Ağrı topuğa sınırı olup, ısı artışı, ödem hatta kızarıklıkla birlikte olabilir. Ağrı miktarı fazla olan çocuklarda vücut kitle indeksi, boy ve kilonun daha fazla olduğu gösterilmiştir. ${ }^{[11]}$ Fizik bulgu, kalkaneal tüberin mediyaline bastırılınca ağrı oluşmasıdır. Ayırıcı tanıda kalkaneus kisti ve osteomiyeliti dışlanmalıdır. Radyolojik olarak bariz bir bulgu yoktur. Sever apofiziti olan ve olmayan çocuklarda skleroz eşit oranda görülmesine karşın, apofiz fragmantasyonuna Sever hastalığında yüksek oranda rastlanmaktadır (Şekil 3). ileri olgularda ayırıcı tanı için MR görüntüleme yararlı olabilir. Bunlar; stres kırıkları, litik lezyonlar ve osteomiyelittir.

\section{Hastalık Seyri - Tedavi}

Sever apofiziti, matürasyon ve kalkaneal apofizin kapanmasıyla iyileşen sınırlı bir durumdur. Tedavi, 
genellikle semptomatik olarak aktivite kısıtlaması, ayakkabı değişimi, topuk destekleri ve Aşil germe egzersizlerinden oluşur. Yapılan randomize kontrollü bir çalışmada, ilk iki ay topuk desteği kullanılmasının yararı olduğu, sürenin daha uzatılmasının anlamı olmadığı gösterilmiştir. ${ }^{[12]}$ Non steroid anti-inflamatuvar ilaç kullanımı yararlı olabilir. Semptomları devam eden hastalarda, kısa bacak alçı ile ortalama iki ay içerisinde iyileşme ve kademeli olarak aktiviteye geçiş gösterilmiştir. ${ }^{[10]}$ Sever hastalığında cerrahinin bir rolü yoktur.

\section{METATARS DISTAL APOFIZiTi (ISELIN HASTALIĞI)}

Illk olarak 1912'de Iselin tarafından tanımlanmış olan bu hastalık 5. metatars bazisinde insersiyonel apofizde bir stres reaksiyonunun peroneus brevis tendonunun Sharpey liflerinde mikro-kırıklarla birlikte olmasına bağlı olduğu düşünülmektedir. Osgood Schlatter hastalığında olduğu gibi, gerçek osiküller yırtılarak kemik büyümesinin yanında apofize fragmante bir görünüm verebilir. ${ }^{[13]}$

Iselin hızlı büyüme periyodu sırasında ortaya çıkar ve tekrarlayan germelerin çok olduğu sporlarla uğraşan çocuklarda görülür. Kemikleşme 12-13 yaşlarında ortaya çıkarken, füzyon genellikle 17-18 yaşlarında olur.

\section{Klinik Bulgular - Radyoloji}

Hasta çocuk genellikle lateral ayak ortası ağrısı ile başvurur. Fizik muayenede, 5. metatars bazisinde hassasiyet ile birlikte yumuşak doku ödemi ve lateral çıkıntının genişlemesi olabilir. Semptomlar apofız kapanınca geçer. Radyolojik olarak, sekonder ossifikasyon merkezi oblik grafilerde metatars uzun aksında paralel bir kemik kıymığı şeklinde görülür. Bu görünüm sağlam çocuklarda da olabileceği için, bulgunun klinikle desteklenmesi gereklidir. ${ }^{[14]}$ Diğer radyolojik bulgular genişleme, fragmantasyon ve kondroosseöz bileşkenin genişlemesidir. MR görüntüleme de $T 2$ ve STIR sekanslarda sinyal artışı ile kemik ödemini gösterecektir. ${ }^{[15]}$

Ayırıcı tanıda, Jones kırı̆̆ı, avulsiyon kırı̆̆ı, stres kırığı ve os vesalianum yer alır (Şekil 4). Travma ve krepitasyonun olmaması apofizit lehinedir. ${ }^{[15]}$ Radyolojik bulgunun yerleşim yeri kırıklarda horizontaldir ve eklem içine de uzanır. ${ }^{[15]}$ Diğer bir bulgu olan os vesalianum, peroneus brevis içerisinde yer alan bir sesamoid kemik olup 5. metatars bazisinin daha proksimalinde düzgün yüzeyli ve sklerotik olarak görülür. Şüphe durumunda, diğer tarafın grafisinin çekilmesi veya MR yararlı olacaktır.

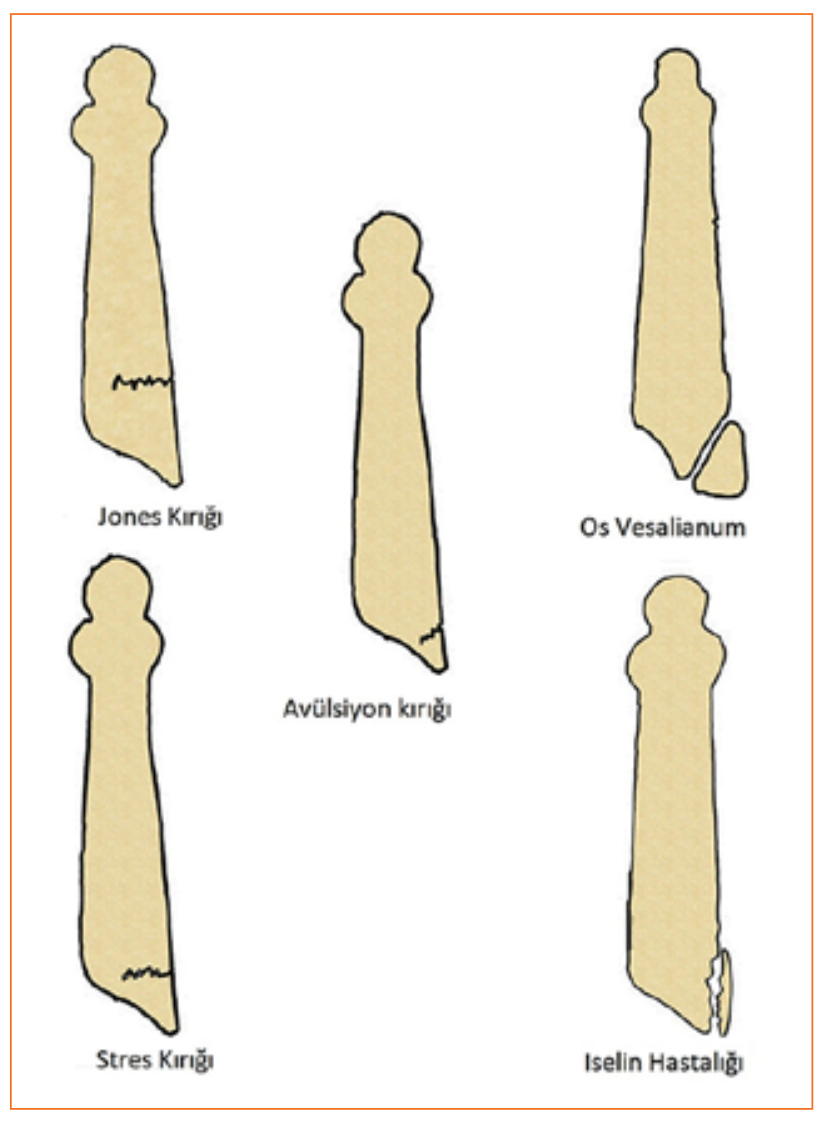

Şekil 4. Iselin hastalığı görsel ayırıcı tanısı (Kishan TV, et al. ${ }^{[14]}$ Iselin's disease: Traction apophysitis of the fifth metatarsal base, a rare cause of lateral foot pain. M J Armed Forces India 2016;72(3):299-301 kaynak alınarak yeniden çizilmiştir).

\section{Hastalık Seyri - Tedavi}

Hastalık bulguları apofizin kaynaması ile kaybolur. Tedavisi; analjezikler, buz uygulaması ve spor aktivitelerinin kısıtlanması ile semptomları ileri hastalarda alçı immobilizasyonu şeklindedir. ${ }^{[4,14]}$ Nonunion ile giden olgularda, ağrılı ise fragman eksizyonu yapılabilir. ${ }^{[14]}$

\section{METATARS BAŞI AVASKÜLER NEKROZU (FREIBERG HASTALIĞI)}

Freiberg 1914 yılında, 2. Metatars başında kıkırdak yüzeyin düzleşmesi ve litik sklerotik alanlar görülmesiyle karakterize ağııı bir durum tanımlamıştır. ${ }^{[16]}$ Kullanılan infraksiyon terimi travmayı işaret ederken infarkt terimi daha çok iskemik bir etiyolojiyi tanımlar. Hastalığın rastlanma sıklığı bilinmemesine karşın, daha çok adolesan kızlarda görülmektedir. En sık 2. metatars başı, daha sonra 3. metatars başı tutulur. Hastaların \%10'undan azında bilateral tutulum vardır. Hastalığın gerçek nedeni bilinmemesine karşın, 
Tablo 1. Freiberg Hastalığında Smillie sınıflaması ${ }^{[18]}$

\begin{tabular}{cl}
\hline Evre & Özellik \\
\hline I & Epifizden geçen belirsiz kırık hattı. \\
II & Erken çökme ve merkezde ezilme. \\
III & Merkezi ezilme mediyal ve lateral kenarlara uzanır ancak plantar menteşe sağlamdır. \\
IV & Merkezi bölüm plantar menteşeden kurtulur, serbest cisimcik oluşur ve lateral ve mediyal kısımlar kırılır. \\
V & Metatars başı yassılaşarak sekonder dejeneratif değişiklikler oluşur.
\end{tabular}

enkondral ossifikasyonun bozulması nedeniyle osteokondrozlar altında sınıflanır. Teorik olarak, travma, stres tekrarı, vasküler anormallikler veya yüksek topuklu ayakkabılara bağlı olduğu düşünülmektedir. ${ }^{[4]}$

\section{Klinik Bulgular - Radyoloji}

Tipik hastalar, spor aktiviteleri veya basmakla ağrısı artan adolesan kızlardır. Fizik muayenede, 2. veya 3. metatars başında hassasiyet ve bazen 2 . sıranın kısalığı saptanır. Grafilerde, 2. metatarsofalengeal eklemin genişlediği ve metatars başının çöktüğü ve skleroze olduğu görülür. Metatars başının düzensizliği ve düzleşmesine ek olarak dorsal çıkıntı da oluşabilir. İkincil olarak, eklemde serbest cisimler ve metatars gövdesinin kalınlaşması görülebilir (Şekil 4). Bu anlamda, Perthes hastalığının ayakta görülen formu olarak da adlandırılır. ${ }^{[5]}$ Smillie, 1967'de radyolojik bir sınıflama oluşturmuştur (Tablo 1). ${ }^{[17]}$

Ayırıcı tanıda, sinovit, Morton nörinomu ve metatarsal stres kırığı yer alır. MR görüntüleme, özellikle erken evrede, eklemde artritik değişiklikler oluşmadan tanı koymada yardımcıdır. T1 sekanslarda epifizde hipointens, T2 sekanslarda da karışık olarak hipo ve hiperintens sinyaller görülür (Şekil $5 \mathrm{a}$ ve $5 \mathrm{~b}$ ).
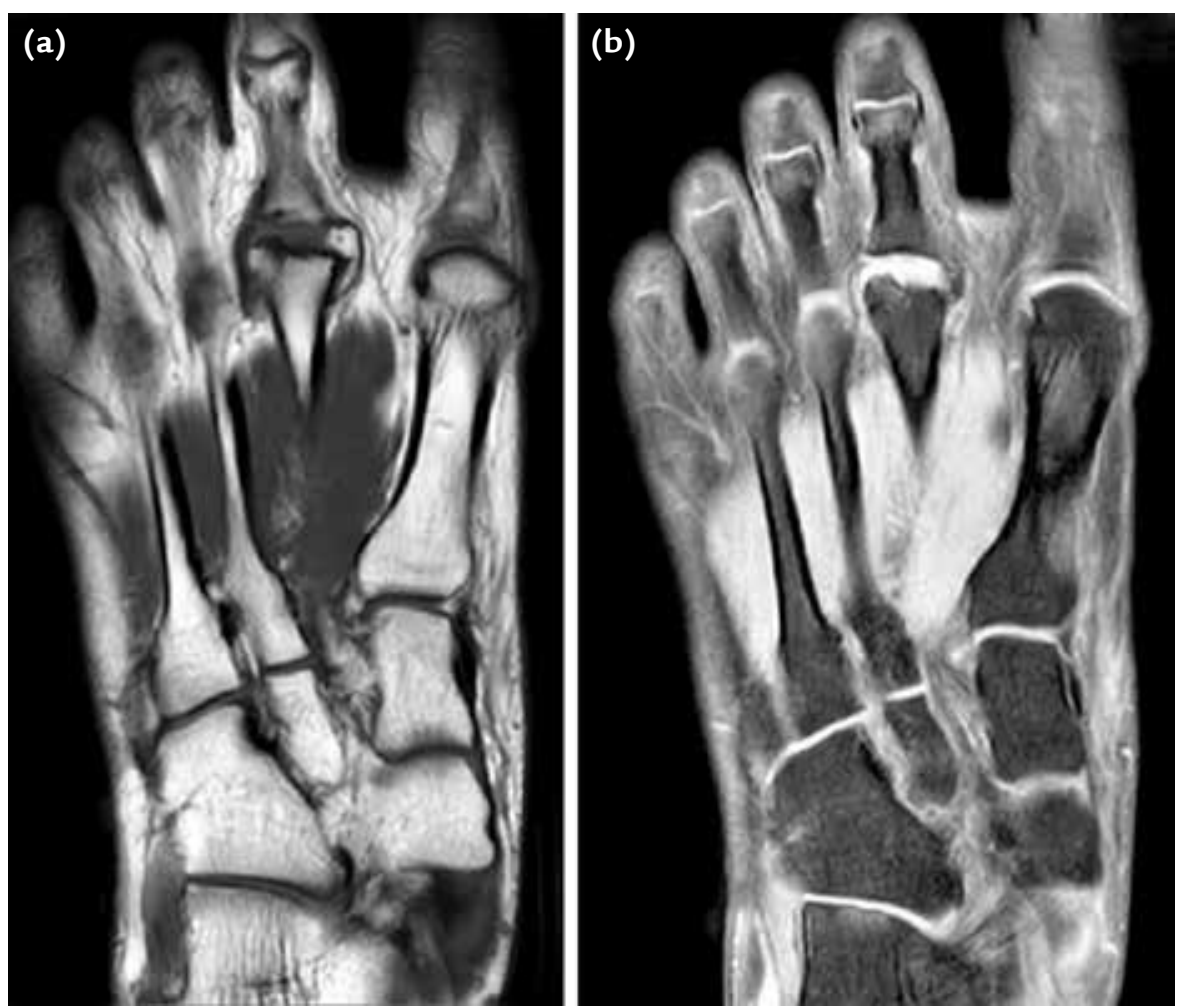

Şekil 5. Smillie Evre 4 MR bulguları. T1 sekansda çökme, serbest cisim ve mediyal ve lateral genişlemeler görülüyor (a). T2 sekansda kemik ödemi ve eklem içi ödem göz çarpıyor (b). 


\section{Hastalık Seyri - Tedavi}

Hastalık, tanımlanmış evreleri tamamlayarak ağrının geçmesi ve eklem yüzeyinin tamiri ile sonlanır. Uzun süreli sonuçlar eklem yüzeyinin aldığı hasara ve serbest cisimcik oluşumuna bağlıdır. Erken dönemde konservatif tedavide destekli veya desteksiz 4-6 hafta immobilizasyon önerilir. Bu tedavi, özellikle eklem içi hasarın olmadığı akut faz olguları için yararlıdır. Destek olarak nonsteroid anti-inflamatuvar ilaçlar ve fizik tedavi uygulanabilir. Bu süre içinde fiziksel aktivite mümkün olduğu kadar sınırlanmalıdır. Semptomlar azaldıktan sonra kademeli olarak fiziksel aktiviteye dönüş sağlanır. Reossifikasyon ve radyolojik değişikliklerin düzelmesi yaklaşık 2-3 yıl alır. ${ }^{[2]}$ Yüksek topuklu ayakkabı giyilmesi engellenmelidir. Metatarsofalangeal eklemi yükten kurtaracak ortez ve ayakkabı modifikasyonları yapılmalıdır.

Cerrahi tedavi, konservatif başarısız kalırsa uygulanır. Cerrahiler, eklem koruyucu ve eklem destrüksiyonu olarak iki ana grupta incelenir. 2017'de Schade'nin yaptığı bir sistemik derlemede, eklem koruyucu cerrahi gerçekleştirenlerin daha fazla yayın yaptığı, toplam 257 koruyucu cerrahinin ortalama 30,4 ay takibinde \%90'dan fazla ağrı azalması ve aktiviteye tam dönüş olduğu, buna karşın eklem destrüksiyonu içeren toplam 70 olgunun ortalama 15 ay takibinde $\% 70$ iyi sonuç alındığı bildirilmiştir. ${ }^{[18]}$ Burada gözetilmesi gereken, metatars başı beslenmesinin bozulmamasıdır.

\section{EKLEM DEBRIDMANI}

Eklem koruyucu cerrahide eklem debridmanı, sinoviyektomi, serbest cisimciklerin eksizyonu, lateral ve mediyal osteofitlerin ve çıkıntıların alınması şeklindedir. Helal ve Gibb 1987'de, Evre I ve II hastalarda greftleme ile birlikte eklemdeki çökmenin kaldırılması, buna karşın daha ileri olguların hasta semptomlarına göre değerlendirilmesi gerektiğini belirtmişlerdir. Bası metatarsaljisi olan hastalarda osteotomiyi önerirlerken, eklem hareket açıklığı ve artritik değişikliklerden etkilenenlerde de artroplastiyi tercih etmişlerdir. ${ }^{[19]}$ Erdil ve arkadaşları ise eklem debridmanı ile 14 ileri evre hastada iyi sonuç aldıklarını bildirmişlerdir. ${ }^{[20]}$

\section{KEMIK GREFTLEME}

Smillie orijinal makalesinde, çökmüş kıkırdağı kaldırmak için metatars şaftına bir delik açarak sklerotik kemiğin delindiği, kıkırdağın kaldırılarak kemik grefti ile doldurulduğu bir yöntem tanımlamıştır. Bu yöntemin kullanılması, Evre I, II ve III hastalarda kıkırdak örtü sağlam ise mümkündür. ${ }^{[17,18]}$ Helal ve Gibb, 1987'de bu yöntemi modifiye ederek, 25 hastayı ameliyat etmiş ve sekiz hastanın 3-8 yıllık takibinde klinik ve radyolojik olarak normal olduklarını belirtmişlerdir. Üç hastada metatars başının genişlediğini, üç hastada da koşu ve yüksek topuklu ayakkabı ile ağrı oluştuğunu görmüşlerdir. ${ }^{[19]}$

\section{OSTEOTOMi}

Birçok farklı osteotomi tanımlanmıştır. Amaç, hasarlı olan kıkırdak yüzeyin yükten kurtarılmasıdır. En sık olarak dorsifleksiyon ve kısaltma osteotomisi kullanılır. Bu iki yöntemi karşılaştıran bir çalışmada, Özkul ve arkadaşları, Evre IV ve V olan 16 hastada ortalama 30,8 ay takip sonunda benzer iyi sonuçlar bulmuşlar ve kısaltma osteotomisinin eklem hasarının çok ileri olgulara yapılmasının daha doğru olacağını, kısaltma yapılan hastalarda kozmetik şikayet oluşabileceğini vurgulamışlardır. ${ }^{[21]}$ Chao ve arkadaşları ise, 13 hastada dorsal kapayıcı kama osteotomisine sinoviyektomi ve debridmanı ekleyerek, tüm evrelerde yaptıkları ortalama 40 ay takipli çalışmalarında, dört mükemmel, yedi iyi ve iki kötü sonuç bildirmişlerdir. ${ }^{[22]}$ Kısaltması $3 \mathrm{~mm}$ olan bir hastada transfer metatarsalji oluşmuştur. Helix-Giardonino ve arkadaşlarının yayımladığı 30 olguluk ortalama 6,5 yıllık takipli seride; 17 hastada mükemmel, 11 hastada tatminkar ve iki hastada orta derecede tatminkar sonuç elde edilmiştir. ${ }^{[23]}$ Yazarlar, eklem şeklini korunması için bu osteotomiyi özellikle tavsiye etmektedirler (Şekil 6).

\section{ARTROPLASTI}

Rezeksiyon artroplastisi, ilk tedavi şemalarında yer alsa da günümüzde terk edilmiş gibidir. İki yöntem kullanılır: birisi proksimal falanks bazisinin, diğeri ise metatars başının rezeksiyonudur. Açık veya artroskopik olarak yapılabilir. Yöntem kalıcı kısalığa yol açtığından, biyomekanik olarak transfer lezyonlarına neden olmaktadır. Aşırı kısaltma ve ilerleyici halluks valgus, diğer komplikasyonları arasındadır.

İnterpozisyon artroplastisi de bildirilen yöntemlerden birisi olmasına karşın, sonuçları çok değişkenlik göstermektedir. ${ }^{[18]}$ Total küçük eklem artroplastisi, ilk başlarda el için tasarlanmış silikon implantlarla başlamış, son yıllarda titanyum hemi veya total seramiklere dönmüştür. Potansiyel avantajları arasında; uzunluğun korunması, eklem hareketinin düzelmesi ve kondillerin korunması durumunda daha iyi yük dağılımı vardır. Olası komplikasyonları arasında; implant gevşemesi, kemik erozyonu, enfeksiyon ve sert yüzen parmak yer almaktadır. ${ }^{[24,25]}$ 

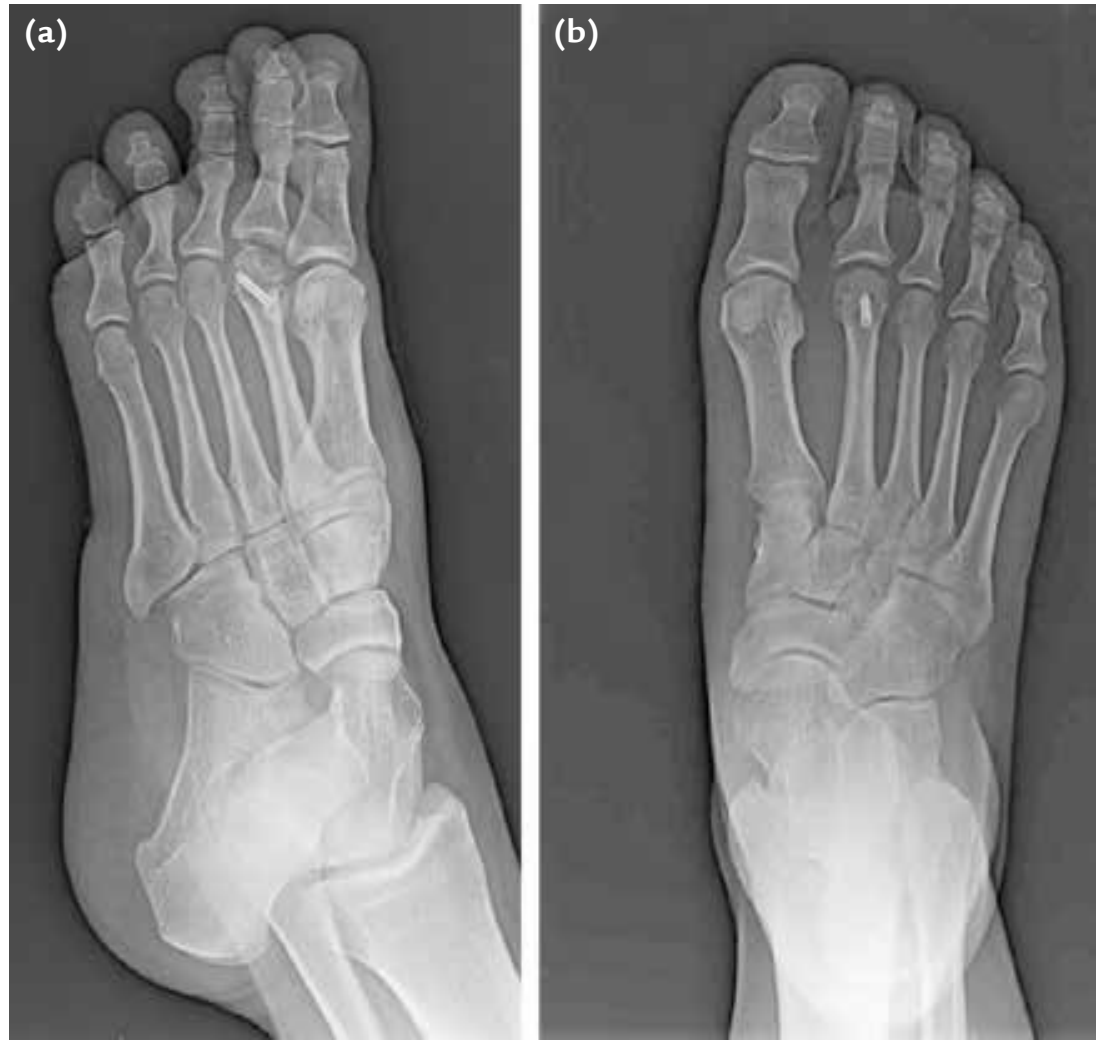

Şekil 6. Yirmi üç yaşında kadın; Smillie Evre 4 dorsifleksiyon osteotomisi; erken postop (a); birinci yıl kontrol grafisi (b).

\section{DiĞER YÖNTEMLER}

Diğer kullanılan yöntemler arasında, debridmana ek olarak, mikro-drilleme, artroskopik mikro-drilleme, geç evrelerde osteokondral greft transferi sayılabilir. Tüm bu yöntemler, literatürde olgu sunumu veya serileri olarak bildirilmiş olup kanıt düzeyleri düşüktür. ${ }^{[18]}$

\section{SONUÇ}

Çocukluk çağı osteokondrozlar ve apofizitlerinin iyi bilinmesi, özellikle spor yapan pediatrik grubun artması ile, klinik uygulamalarda erken tanı ve tedavi sağlayarak erken spora dönüş ve hasta memnuniyeti sağlayacaktır. Birçoğu konservatif tedaviye yanıt veren bu patolojilerde, uzun dönemde iyi sonuçlar alınabilmesi bu konudaki farkındalığa bağlıdır.

\section{KAYNAKLAR}

1. Duthie RB, Houghton GR. Constitutional aspects of the osteochondroses. Clin Orthop Relat Res 1981;(158):19-27.

2. Gillespie $H$. Osteochondroses and apophyseal injuries of the foot in the young athlete. Curr Sports Med Rep 2010;9(5):265-8. Crossref
3. Atanda A Jr, Shah SA, O'Brien K. Osteochondrosis: common causes of pain in growing bones. Am Fam Physician 2011;83(3):285-91.

4. Ippolito E, Ricciardi Pollini PT, Falez F. Köhler's disease of the tarsal navicular: long-term follow-up of 12 cases. J Pediatr Orthop 1984;4(4):416-7.

5. Kasser JR. The Foot. In: Lovell and Winter's Pediatric Orthopaedics, Lovell WW, Winter RB, Morrissy RT, Weinstein SL, editors. Philadelphia: Lippincott Williams \& Wilkins; 2006. p.1317-21.

5. Karp M, Meier G. Köhler's disease of the tarsal scaphoid: an end-result study. J Bone Joint Surg Br 1937.

6. Kidner F, Muro F. Kohler's disease of the tarsal scaphoid or os navicular pedis retardatum. JAMA 1924;83:650.

7. Borges JL, Guille JT, Bowen JR. Köhler's bone disease of the tarsal navicular. J Pediatr Orthop 1995;15(5):596-8.

8. DiGiovanni CW, Patel A, Calfee R, Nickisch F. Osteonecrosis in the foot. J Am Acad Orthop Surg 2007;15(4):208-17.

9. Clark MC. Overview of the causes of limp in children. UpToDate Online. http://www.uptodate.com/online/content/topic. do?topicKey=ped_symp $/ 5916$

10. Liberson A, Lieberson S, Mendes DG, Shajrawi I, Ben Haim $\mathrm{Y}$, Boss $\mathrm{JH}$. Remodeling of the calcaneus apophysis in the growing child. J Pediatr Orthop B 1995;4:74-9.

11. James AM, Williams CM, Luscombe M, Hunter R, Haines TP. Factors associated with pain severity in children with calcaneal apophysitis (sever disease).J Pediatr 2015;167(2):455-9. Crossref 
12. James AM, Williams CM, Haines TP. Effectiveness of footwear and foot orthoses for calcaneal apophysitis: a 12-month factorial randomised trial. Br J Sports Med 2016;50(20):1268-75. Crossref

13. Ralph BG, Barrett J, Kenyhercz C, DiDomenico LA. Iselin's disease: a case presentation of nonunion and review of the differential diagnosis. J Foot Ankle Surg 1999;38(6):409-16.

14. Kishan TV, Mekala A, Bonala N, Sri Pavani B. Iselin's disease: Traction apophysitis of the fifth metatarsal base, a rare cause of lateral foot pain. M J Armed Forces India 2016;72(3):299301. Crossref

15. Gupta N, Sharma K, Bansal I, KumarY, Hayashi D. Kickboxing power hour: case report of fifth metatarsal apophysitis (Iselin disease) and its magnetic resonance imaging features. Transl Pediatr 2017;6(2):98-101. Crossref

16. Freiberg $\mathrm{AH}$. Infraction of the second metatarsal bone,a typical injury. Surg Gyn Ob 1914;19:191.

17. Simillie IS. Treatment of Freiberg's infraction. Proc R Soc Med 1967;60(1):29-31.

18. Schade VL. Surgical Management of Freiberg's Infraction: A Systematic Review. Foot Ankle Spec 2015;8(6):498-519. Crossref

19. Helal B, Gibb P. Freiberg's disease: a suggested pattern of management. Foot Ankle 1987;8(2):94-102.
20. Erdil M, Imren Y, Bilsel K, Erzincanli A, Bülbül M, Tuncay I. Joint debridement and metatarsal remodeling in Freiberg's infraction. J Am Podiatr Med Assoc 2013;103(3):185-90.

21. Özkul E, Gem M, Alemdar C, Arslan H, Boğatekin F, Kişin B. Results of two different surgical techniques in the treatment of advanced-stage Freiberg's disease. Indian J Orthop 2016;50(1):70-3. Crossref

22. Chao $\mathrm{KH}$, Lee $\mathrm{CH}$, Lin LC. Surgery for symptomatic Freiberg's disease: extraarticular dorsal closing-wedge osteotomy in 13 patients followed for 2-4 years. Acta Orthop Scand 1999;70(5):483-6.

23. Helix-Giordanino M, Randier E, Frey S, Piclet B. French association of foot surgery (AFCP). Treatment of Freiberg's disease by Gauthier's dorsal cuneiform osteotomy: Retrospective study of 30 cases. Orthop Traumatol Surg Res 2015;101(6 Suppl):S221-5. Crossref

24. Shih AT, Quint RE, Armstrong DG, Nixon BP. Treatment of Freiberg's infraction with the titanium hemi-implant. J Am Podiatr Med Assoc 2004;94(6):590-3.

25. Townshend DN, Greiss ME. Total ceramic arthroplasty for painful, destructive disorders of the lesser metatarsophalangeal joints. Ophthalmology Retina 2007;17(2):73-5. 